\title{
Analysis of Antimicrobial Medications Consumption in Inpatient Units at North West (Tabuk) Region Hospitals, Saudi Arabia
}

\begin{abstract}
Abeer Hussin Almasoudi, Director, Administration of Research and Studies, Ministry of Health, Tabuk, SAUDI ARABIA.

Yousef Ahmed Alomi* ${ }^{\text {iD }}$, The Former General Manager of General Administration of Pharmaceutical Care, Former Head, National Clinical Pharmacy and Pharmacy Practice, Former Head, Pharmacy R\&D Administration, Ministry of Health, Riyadh, SAUDI ARABIA.

Ghormallah Abdullah Alghamdi, Consultant Family Medicine, General Manager of Health Affairs in Tabuk Region, Ministry of Health, Tabuk, SAUDI ARABIA.

Rasha Saad Alshahrani, Clinical

Pharmacy Staff, Ministry of Health, Riyadh, SAUDI ARABIA.
\end{abstract}

\section{Correspondence:}

Yousef Ahmed Alomi, (Bsc. Pharm, MSc. Clin Pharm, BCPS, BCNSP, DiBA, CDE) The Former General Manager of General Administration of Pharmaceutical Care, Former Head, National Clinical Pharmacy and Pharmacy Practice, Former Head, Pharmacy R\&D Administration, Ministry of Health, Riyadh, SAUDI ARABIA.

Phone no: +966 504417712

E-mail:yalomi@gmail.com

Received: 05-02-2019;

Accepted: 27-03-2019

Copyright: $\odot$ the author(s),publisher and licensee Pharmacology, Toxicology and Biomedical Reports. This is an open-access article distributed under the terms of the Creative Commons Attribution NonCommercial License, which permits unrestricted non-commercial use, distribution, and reproduction in any medium, provided the original work is properly cited.

This is an open access article distributed under the terms of the Creative Commons Attribution-NonCommercial-ShareAlike 4.0 License

Access this article online

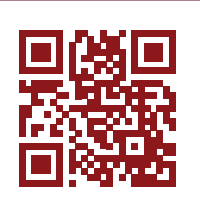

www.ptbreports.org

DOI:

10.5530/PTB.2019.5.24

\begin{abstract}
Background: This article aims to explore antimicrobial medication consumption and related cost among different age groups in inpatient units at North West Region Hospitals, Ministry of Health, and Saudi Arabia. Objectives: To explore the selected antimicrobial medication consumption in inpatient units at North West Region Hospitals, Ministry of Health, Saudi Arabia. To increase the awareness of antimicrobial medication consumption side effect. Methods: It is a 9-month study about antimicrobial drug use by inpatients at North West region hospitals. It included inpatient department for adults, pediatrics and neonates. The medications were selected by Central Antibiotics committee at $\mathrm{MOH}$ as part of the National Antimicrobial Stewardship program. The consumption is driven from pharmacy database and calculated based on off-stranded unit of antimicrobial per hospital. The antimicrobials consisted of antibacterial drugs, antifungal and antiviral medications. The cost of antimicrobial consumption was calculated by using Ministry of Health National Cost database. All cost used as US currency. Results: The total number of Antimicrobial standard units was $(25,845)$ and average $(5,169)$ per hospital. The highest drug consumption was Ceftriaxone $1 \mathrm{gm}$ injection $(3,712)$ followed by Ceftazidime $1 \mathrm{gm}$ injection (1807) and Gentamicin IV $80 \mathrm{mg}(1,011)$ at adult's inpatient wards. The total cost of Antimicrobial consumption was $(6,829,003.42$ USD) and $(1,365,800.68$ USD) per hospital. The highest cost medication consumption from Adults inpatient departments was $99.62 \%(6,803,229.92$ USD) followed by pediatrics inpatient $0.24 \%(16,087.6$ USD) and Neonatal inpatient departments $0.14 \%$ (9,685.9 USD). The highest medication cost was for very broad-spectrum antibiotics like Meropenem, Imipenem and Ceftriaxone. It consumed more than $50 \%$ of the cost burden. Conclusion: There was very high consumption of antimicrobial drugs inpatient department with huge cost burden. Urgent application of antimicrobial stewardship program especially adults' inpatients departments is a mandate and urgent.

Keywords: Antimicrobial, Medications, Consumption, Inpatient, North West (Tabuk), Hospitals, Ministry of Health, Saudi Arabia.
\end{abstract}

\section{INTRODUCTION}

During the $21^{\text {st }}$ century, Antimicrobial Resistance (AMR) has appeared as one of the greatest public health challenges worldwide. AMR is defined as the capability of a microorganism to endure or grow in the occurrence of a concentration of antibiotics that should be sufficient to confine or kill that organism. Antimicrobials have been in use for thousands of years in a variety of formats, it's always considered one of the best and fascinating discoveries of the $20^{\text {th }}$ century and it is the most active chemotherapeutic among drugs. Exacerbating factors responsible for the expansion of AMR include poor information, misunderstandings, views on infectious diseases, unsuitable prescription and medication use and patient request. They act as bacteriostatic agents, restricting growth and reproduction of bacteria and as bactericidal agents causing bacterial cell death. Infections were the primary cause of death during the nineteenth century, the discovery of antibiotics not only helped in the treatment of infections but also have the most significant role in decreasing mortality and morbidity since $1910{ }^{1}$ In 1910, Paul Ehrlich developed the first antimicrobial arsphenamine for the treatment of syphilis, a disease that was almost incurable back then. In 1932 a sulfonamide antibiotic was discovered. During the second half of the nineteenth century and before the critical discovery of Fleming many researchers recorded observations regarding the antibacterial properties of Penicillium fungi. In 1929, Alexander Fleming introduced "penicillin" as a compound with antibacterial properties and Pyocyanase was probably the first antibiotic to be used to treat human infections. ${ }^{1}$

So, the exploration of antibiotic was of significant help in the medical world and pharmacology. There are also good historical events to discover antibiotics. It is very impressive how the discoverers developed raw materials to drugs and how we have moved from a clever use of agents available in the environment to chemically engineered agents to preserve human life. Unfortunately, antibiotic resistance in hospitals, communities and the environment concomitant with their use is in the rising. It created a new challenge for the doctors and pharmacists. The successful use of any therapeutic agent is compromised by the potential development of tolerance or resistance to that compound from the time it is first employed. ${ }^{1}$ The antibiotic resistance has increased in the Kingdom of Saudi Arabia. ${ }^{2-4}$ The resistance could be and due to critical care bugs or inpatient and ambulatory care bugs. Usually, the patients regularly visit the emergency services at the hospitals to seek help for his or her illness condition. 
If the patient does not go for critical care hospital admission, then he/ she will be admitted to inpatient services. Most of the medical diseases that required inpatient hospital admission was an infectious illness. During inpatient admission, the patient is receiving antibiotics as empirical therapy. Several studies showed that antibiotics consumption was related to economic burden on the health care system at inpatient hospitals services. ${ }^{5-13}$ Also showed the determination of antibiotics consumption to measure mis use of antibiotics and financial burden on the health care system. Besides, to investigate the demand for antibiotics stewardship services. ${ }^{14-16}$ Based on the author's best knowledge they are not familiar with any investigation about antibiotics consumption and economic burden at inpatient hospital services in Saudi Arabia or Gulf and the Middle East countries. The goal of the study is to explore the antibiotics consumption at inpatient hospitals services in the North West region (Tabuk) in the Kingdom of Saudi Arabia.

\section{METHODS}

It is a 9-month antimicrobial drug used through inpatient wards at North West region hospitals which includes all adults, pediatrics and neonatal population. Five hospitals were included included of which hospital 1 has been establish in 1980 to serve 100 beds and its serves the maternities and pediatrics. Hospital 2 was hospital established in 1990, with the pharmacy care having many departments including, which they are inpatient, outpatient, narcotics, drug information center, clinics and emergency and serve 100 beds, also has most specialties (pediatrics, OR, ICU, ER, nursery, AKU, and SW). Hospital 3 build was built up in 1983, which is containing 100 beds, all also all specialties are available except chemotherapeutic department. The pharmacy have several departments, which they are inpatient, outpatient, narcotics and emergency pharmacy. Hospital 4 was started in 1991, the capacity of the hospital is 200 bed, which is the largest in the region and also it does contain verities of specialized and served 7 departments. The pharmacy care units containing five departments which are inpatient, outpatient, narcotics, information center, emergency and clinics department. Hospital 5 hospital was established in 2005, which is the newest although the pharmacy serves 100 beds with different departments, they are including inpatient inpatient, outpatient, information centers, narcotics, emergency and clinics, also cover 9 types of wards as the most hospitals in the region. Antibiotics committees were formulated at the above mentioned hospitals through a letter of recommendation which was sent by the General Administration of Pharmaceutical Care at the Ministry of Health for Tabuk Region on October 2013, which stipulates the importance of forming a specialized committee on antibiotics under the supervision and follow up of the department of pharmacy care in the region. Letters of formation of the Antibiotics Committee were sent to all hospitals in Tabuk region in January 2014. In March 2014, this committee was approved by the Director General of Health Affairs in Tabuk Region and guidance to start the application of antibiotics in all hospitals in the region. The actual implementation of the program began in January 2015. The objective of the antibiotic committees was to improve antimicrobial use for hospitalized adults and minimize the emergence and spread of antimicrobial resistance. The objective of the antibiotic committees was to improve antimicrobial use for hospitalized adult and minimizing the emergence and spread of antimicrobial resistance. While the functions of each committees were Supervising the assessment and application of antibiotic strategies in hospitals which are designed by the Antibiotics Committee of the Ministry. Preparation of quarterly reports on the implementation of strategies for the use of antibiotics in hospitals and discussed with the Committee of Pharmacy and therapeutics in the regions. Preparation of bacterial resistance statistics for antibiotics in the area and follow-up and updating. Supervising the training of medical staff (doctors, pharmacists, nurses, specialists, technicians) on the optimal use of antibiotics.
Visits to hospitals to ensure the accuracy and validity of the implementation of strategies. Review and analyze indicators of the application of strategies for the use of antibiotics and consider their development in the region of Tabuk. And writing the annual report on the performance, productivity and impact of the program in the region of Tabuk. The antibiotics medications were selected by Central Antibiotics committee at $\mathrm{MOH}$ as part of the National Antimicrobial stewardship program. The consumption is driven from pharmacy database and calculated based on off stranded unit of antimicrobial per hospital. The antimicrobials consisted of antibacterial drugs, antifungal and antiviral medications. The cost of antimicrobial consumption was calculated by using Ministry of Health National Cost database. All cost used was as US currency.

\section{RESULTS}

The total number of hospitals were five. Hospitals with (100-300 beds) represented $80 \%$ while those with (50-99 beds) were $20 \%$. All hospitals (100\%) were accredited by Saudi Board of Hospital Accreditation (CBAHI) while none (0\%) of the hospital was accredited by International Joint Commissions. The total response month's rate was $110(81.48$ $\%)$ that's included adults response rate $40(88.88 \%)$, pediatrics response rate $38(84.44 \%)$ and neonates response rate $32(71.11 \%)$ (Table 1$)$. The total number of Antimicrobial standard units was $(25,845)$ and average $(5,169)$ per hospital. The highest units' consumption was adults inpatient wards 15,695 (60.73\%) followed by pediatrics wards 7,408 (28.66\%) and neonates wards $2,731(10.57 \%)$. The highest drug consumption was Ceftriaxone $1 \mathrm{gm}$ injection $(3,712)$ followed by Ceftazidime $1 \mathrm{gm}$ injection (1807) and Gentamicin IV $80 \mathrm{mg}(1,011)$ at adult's inpatient wards. The highest drug consumption was Ceftriaxone $1 \mathrm{gm}$ injection $(4,268)$ followed by Azithromycin PO $200 \mathrm{mg} / 15 \mathrm{ml}$ suspension (376) and Acyclovir IV $250 \mathrm{mg}$ (257) at pediatrics' inpatient wards. The highest drug consumption was Ceftriaxone $1 \mathrm{gm}$ injection (592) followed by Gentamicin IV $20 \mathrm{mg}$ (429) and Vancomycin IV $500 \mathrm{mg}$ (175) at neonates' inpatient wards. The total cost of Antimicrobial consumption was $(6,829,003.42$ USD) and $(1,365,800.68$ USD) per hospital. The highest cost medication consumption from Adults inpatient departments was $99.62 \%(6,803,229.92$ USD) followed by pediatrics inpatient $0.24 \%$ $(16,087.6$ USD) and neonatal inpatient departments $0.14 \%(9,685.9$ USD). The highest drug cost consumption was Ceftriaxone 1 gm injection $(1,626,152.96$ USD) followed by Meropenem IV 500mg injection $(1,527,552.00$ USD) and Imipenem + Cilastatin IV $500 \mathrm{mg}(1,443,706.00$ USD) at adult's inpatient wards. The highest drug cost consumption was Meropenem IV $1 \mathrm{~g}$ injection (3,813.81 USD) followed by Ceftriaxone IV $1 \mathrm{~g}(3,158.32 \mathrm{USD})$ and Imipenem + Cilastatin IV $500 \mathrm{mg}(2,772.00$ USD) at pediatrics' inpatient wards. The highest drug cost consumption was Meropenem IV $1 \mathrm{~g}$ (2,320.29 USD) followed by Meropenem IV 500 $\mathrm{mg}(2,121.60 \mathrm{USD})$ and Imipenem + Cilastatin IV $500 \mathrm{mg}(1,507.00$ USD) at neonates' inpatient wards. The highest medication cost was very broad-spectrum antibiotics like Meropenem, Imipenem and Ceftriaxone. It consumed more than $50 \%$ of the cost burden (Table 2).

\section{DISCUSSION}

The antibiotics stewardship program should be implemented at several departments including the intensive care services, ambulatory care clinics, emergency services and inpatient departments. Each service had particular requirements for antibiotics prescribing guidelines and infectious diseases management. Besides, the type of antibiotics with dosage forms is different from department to services. The necessary information of antibiotics consumption is essential to establish the antibiotics stewardship program at inpatient services. The study was conducted to explore the necessary information. It showed the high antibiotics consumption was adults followed by pediatrics and neonates. This is expected due to 
Table 1: Hospitals demographic data.

\begin{tabular}{|c|c|c|c|c|c|c|}
\hline & Hospital 1 & Hospital 2 & Hospital 3 & Hospital 4 & Hospital 5 & Total \\
\hline \multicolumn{7}{|l|}{ No of Beds } \\
\hline \multicolumn{7}{|l|}{$<50$} \\
\hline $50-99$ & & & & YES & & $1(20 \%)$ \\
\hline $100-300$ & YES & YES & YES & & YES & $4(80 \%)$ \\
\hline \multicolumn{7}{|l|}{$301-400$} \\
\hline \multicolumn{7}{|l|}{$401-500$} \\
\hline CIBAHI & Yes & Yes & Yes & Yes & Yes & $5(100 \%)$ \\
\hline JCI & No & No & No & No & No & $0(0 \%)$ \\
\hline \multicolumn{7}{|c|}{ Repose Rate } \\
\hline \multicolumn{7}{|l|}{ ICU units } \\
\hline Adults & 9 & 9 & 4 & 0 & 9 & $31(68.88 \%)$ \\
\hline Pediatrics & 0 & 6 & 4 & 0 & 8 & $18(40 \%)$ \\
\hline Neonates & 2 & 4 & 4 & 0 & 9 & $19(42.22 \%)$ \\
\hline Total & 11 & 19 & 12 & 0 & 26 & $68(50.37 \%)$ \\
\hline \multicolumn{7}{|c|}{ Inpatient wards } \\
\hline Adults & 9 & 9 & 4 & 9 & 9 & $40(88.88 \%)$ \\
\hline Pediatrics & 7 & 9 & 4 & 9 & 9 & $38(84.44 \%)$ \\
\hline Neonates & 3 & 9 & 4 & 9 & 7 & $32(71.11 \%)$ \\
\hline Total & 19 & 27 & 12 & 27 & 25 & $110(81.48 \%)$ \\
\hline \multicolumn{7}{|c|}{ OPD clinics } \\
\hline Adults & 9 & 9 & 4 & 0 & 8 & $30(66.66 \%)$ \\
\hline Pediatrics & 6 & 8 & 4 & 1 & 7 & $26(57.77 \%)$ \\
\hline Neonates & 0 & 8 & 4 & 0 & 0 & $12(26.66 \%)$ \\
\hline Total & 15 & 25 & 12 & 1 & 15 & 68 (50.37 \%) \\
\hline \multicolumn{7}{|l|}{ ER units } \\
\hline Adults & 9 & 5 & 4 & 0 & 0 & $18(40 \%)$ \\
\hline Pediatrics & 0 & 9 & 4 & 9 & 0 & $22(48.88 \%)$ \\
\hline Neonates & 0 & 5 & 4 & 0 & 0 & $9(20 \%)$ \\
\hline Total & 9 & 19 & 12 & 9 & 0 & 49 (36.29\%) \\
\hline
\end{tabular}

different disease conditions with different quantity of doses. The most commonly used antibiotic was IV ceftriaxone for adult, pediatrics and neonatal patients that's similar to the previous study of third generation cephalosporin ${ }^{11}$ and with Ceftriaxone usage in pediatrics, ${ }^{10}$ while it differed from other study of using Penicillin at first antibiotics consumption $^{12}$ or Fluoroquinolones or penicillin usage in the different study. ${ }^{13}$ The authors cannot clarify the justification of consumption because of missed diseases information. Besides, the common infectious diseases in adults or pediatrics and neonates admitted to the hospital. The very broad antibiotics like ceftazidime used in adult's patient maybe their gram-negative infection with $P$. Aeruginosa. Gentamicin is used much for adults and neonates as expected because the common diseases of pyelonephritis and neonatal septicemia and this drug is indicated for them. The costly medications are used for all types of patient's including adults, pediatrics and neonates. Few broad antibiotics consumed additional half of the budget like Meropenem, Imipenem and ceftriaxone. The utilization of expensive medications for inpatient services needs clarification and justification. That is different from the previous study that showed
Penicillin and Cephalosporin were high cost consumption ${ }^{12}$ because not used expensive medications. Antibiotics stewardship program is very demanding for inpatient services of North West region hospitals in the Kingdom of Saudi Arabia. ${ }^{14,17}$

\section{CONCLUSION}

The broad-spectrum antibiotics are highly used in the inpatient services at North West region in the Kingdom of Saudi Arabia. Targeting of implantation of Antibiotic stewardship program at inpatient services. Moreover, further studies about antibiotic utilization in such detail is required in the North West region of Saudi Arabia.

\section{ACKNOWLEDGEMENT}

None.

\section{CONFLICT OF INTEREST}

The authors declare no conflict of interest. 
Table 2: Anti-infectious drugs consumption at inpatient general wards.

\begin{tabular}{|c|c|c|c|c|c|c|c|c|c|}
\hline $\begin{array}{l}\text { Quantity consumption Anti- } \\
\text { infectious drugs }\end{array}$ & Dosage Forms & Neonates & cost (USD) & Pediatrics & cost (USD) & Adults & cost (USD) & $\begin{array}{c}\text { Total } \\
\text { Quantities }\end{array}$ & $\begin{array}{l}\text { Total cost } \\
\text { (USD) }\end{array}$ \\
\hline Cloxacillin sodium IV 250mg & Vial or amp. & 4 & 1.56 & 80 & 31.12 & 82 & 127.59 & 166 & 160.27 \\
\hline Flucloxacillin sodium IV $250 \mathrm{mg}$ & Vial or amp. & 0 & 0.00 & 0 & 0.00 & 64 & 0.00 & 64 & 0.00 \\
\hline Piperacillin + Tazobactam IV $2.25 \mathrm{~g}$ & Vial & 60 & 81.60 & 140 & 190.40 & 378 & $30,844.80$ & 578 & $31,116.80$ \\
\hline Piperacillin + Tazobactam IV $4.5 \mathrm{~g}$ & Vial & 53 & 115.90 & 170 & 371.74 & 609 & $70,580.12$ & 832 & $71,067.75$ \\
\hline Ceftazidime IV 1g & Vial & 134 & 100.06 & 206 & 153.82 & 1807 & $180,804.44$ & 2147 & $181,058.32$ \\
\hline Ceftriaxone IV 1g & Vial & 592 & 438.08 & 4268 & 3158.32 & 3712 & $1,626,152.96$ & 8572 & $1,629,749.36$ \\
\hline Cefepime IV 1g & Vial & 30 & 56.28 & 42 & 78.79 & 448 & $25,213.44$ & 520 & $25,348.51$ \\
\hline Cefepime IV $2 \mathrm{~g}$ & Vial & 119 & 412.54 & 168 & 582.41 & 393 & $162,127.16$ & 680 & $163,122.10$ \\
\hline $\begin{array}{l}\text { Imipenem + Cilastatin IV } \\
500 \mathrm{mg}+500 \mathrm{mg}\end{array}$ & Vial & 137 & $1,507.00$ & 252 & 2772.00 & 958 & $1,443,706.00$ & 1347 & $1,447,985.00$ \\
\hline Meropenem IV 500mg & Vial & 156 & $2,121.60$ & 199 & 2706.40 & 720 & $1,527,552.00$ & 1075 & $1,532,380.00$ \\
\hline Meropenem IV 1g & Vial & 87 & $2,320.29$ & 143 & 3813.81 & 480 & $1,113,739.20$ & 710 & $1,119,873.30$ \\
\hline Tigecycline IV 50mg & Vial & 0 & 0.00 & 0 & 0.00 & 10 & 500.00 & 10 & 500.00 \\
\hline Amikacin IV 100mg & Vial or amp. & 51 & 16.52 & 77 & 24.95 & 110 & $1,817.64$ & 238 & $1,859.11$ \\
\hline Amikacin IV 500mg & Vial or amp. & 70 & 31.50 & 130 & 58.50 & 696 & $21,924.00$ & 896 & $22,014.00$ \\
\hline Gentamicin IV 20mg & Vial or amp. & 429 & 257.40 & 155 & 93.00 & 148 & $38,095.20$ & 732 & $38,445.60$ \\
\hline Gentamicin IV 80mg & Vial or amp. & 120 & 72.00 & 127 & 76.20 & 1011 & $72,792.00$ & 1258 & $72,940.20$ \\
\hline Azithromycin PO 250mg & Tablet & 0 & 0.00 & 130 & 9.36 & 797 & 0.00 & 927 & 9.36 \\
\hline Azithromycin PO 200mg/15ml & Suspension & 94 & 89.29 & 376 & 357.16 & 0 & 0.00 & 470 & 446.45 \\
\hline Clindamycin IV 300mg & Ampoule & 70 & 121.31 & 129 & 223.56 & 547 & $66,356.57$ & 746 & $66,701.44$ \\
\hline Vancomycin IV 500mg & Vial & 175 & 236.25 & 237 & 319.95 & 666 & $157,342.50$ & 1078 & $157,898.70$ \\
\hline Linezolid PO 600mg & Tablet & 0 & 0.00 & 0 & 0.00 & 60 & 0.00 & 60 & 0.00 \\
\hline Linezolid IV 600mg & Premixed bag & 0 & 0.00 & 0 & 0.00 & 0 & 0.00 & 0 & 0.00 \\
\hline Linezolid PO 100mg & Suspension & 0 & 0.00 & 0 & 0.00 & 0 & 0.00 & 0 & 0.00 \\
\hline Rifabutine PO 150mg & Tablet & 0 & 0.00 & 0 & 0.00 & 246 & 0.00 & 246 & 0.00 \\
\hline Ciprofloxacin IV 200mg & Bottle & 52 & 38.43 & 85 & 62.82 & 625 & $24,017.50$ & 762 & $24,118.74$ \\
\hline Moxifloxacin IV 400mg & Vial & 5 & 167.50 & 17 & 569.50 & 120 & $20,100.00$ & 142 & $20,837.00$ \\
\hline Moxifloxacin PO 400mg & Tablet & 0 & 0.00 & 20 & 22.60 & 302 & 0.00 & 322 & 22.60 \\
\hline Levofloxacin IV 500mg & Premixed bag & 160 & $1,280.00$ & 0 & 0.00 & 60 & $76,800.00$ & 220 & $78,080.00$ \\
\hline Amphotericin B liposomal 50mg & Vial & 0 & 0.00 & 0 & 0.00 & 0 & 0.00 & 0 & 0.00 \\
\hline Amphotericin B 50mg & Vial & 0 & 0.00 & 0 & 0.00 & 0 & 0.00 & 0 & 0.00 \\
\hline Voriconazole IV 200mg & Vial & 0 & 0.00 & 0 & 0.00 & 0 & 0.00 & 0 & 0.00 \\
\hline Voriconazole PO 200mg & Tablet & 0 & 0.00 & 0 & 0.00 & 0 & 0.00 & 0 & 0.00 \\
\hline Caspofungin IV 50mg & Vial & 0 & 0.00 & 0 & 0.00 & 0 & 0.00 & 0 & 0.00 \\
\hline Micafungin IV $50 \mathrm{mg}$ & Vial & 0 & 0.00 & 0 & 0.00 & 0 & 0.00 & 0 & 0.00 \\
\hline Acyclovir IV 250mg & Vial & 138 & 220.80 & 257 & 411.20 & 646 & $142,636.80$ & 1041 & $143,268.80$ \\
\hline Valaciclovir PO 500mg & Tablet & 0 & 0.00 & 0 & 0.00 & 0 & 0.00 & 0 & 0.00 \\
\hline Artemisinin PO 250mg & Capsule & 0 & 0.00 & 0 & 0.00 & 0 & 0.00 & 0 & 0.00 \\
\hline Artesunate PO 50mg & Tablet & 0 & 0.00 & 0 & 0.00 & 0 & 0.00 & 0 & 0.00 \\
\hline Artesunate IV 60mg & Ampoule & 0 & 0.00 & 0 & 0.00 & 0 & 0.00 & 0 & 0.00 \\
\hline Proguanil PO 100mg & Tablet & 0 & 0.00 & 0 & 0.00 & 0 & 0.00 & 0 & 0.00 \\
\hline $\begin{array}{l}\text { Artemether +Lumefantrine PO } \\
\text { 20/120mg }\end{array}$ & Tablet & 0 & 0.00 & 0 & 0.00 & 0 & 0.00 & 0 & 0.00 \\
\hline \multirow[t]{2}{*}{ Artmether IV 20mg } & Ampoule & 0 & 0.00 & 6 & 0.00 & 0 & 0.00 & 6 & 0.00 \\
\hline & & 2,731 & $9,685.90$ & 7,408 & $16,087.60$ & 15,695 & $6,803,229.92$ & 25,845 & $6,829,003.42$ \\
\hline
\end{tabular}




\section{ABBREVIATIONS}

AMR: Antimicrobial resistance; AMS: National antimicrobial stewardship program; KSA: Kingdom of Saudi Arabia; MOH: Ministry of Health; OR: Operation; ICU: Intensive Care Unit; AKU: Artificial Kidney Unit; SW: Surgical Wards; UDS: Unite State Dollars.

\section{ORCID ID}

Yousef Ahmed Alomi (iD https://orcid.org/0000-0003-1381-628X

\section{REFERENCES}

1. Gould K. Antibiotics: From prehistory to the present day. J Antimicrob Chemother. 2016:71(3):572-5.

2. AlYousef SA. Surveillance of antibiotic-resistant bacteria in King Khalid hospital, Hafr Al-Batin, Saudi Arabia, during 2013. Jundishapur J Microbiol. 2016;9(9):e19552.

3. Lakshmana GK, Marie MAM, Al-Sheikh YA, John J, Gopalkrishnan S, Chikkabidare SP, et al. A 6-year surveillance of antimicrobial resistance patterns of Acinetobacter baumannii bacteremia isolates from a tertiary care hospital in Saudi Arabia during 2005-2010. Libyan J Med. 2014;9:24039.

4. Aly M, Balkhy $\mathrm{HH}$. The prevalence of antimicrobial resistance in clinical isolates from Gulf Corporation Council countries. Antimicrob Resist Infect Control. 2012;1(25):1-5.

5. European Centre for Disease Prevention and Control. Antimicrobial consumption 2016. Annual epidemiological report for 2016. 2018. Available from: https://ecdc europa.eu/sites/portal/files/documents/AER_for_2016-AMC.pdf.

6. European Centre for Disease Prevention and Control. Antimicrobial consumption 2015. Annual epidemiological report for 2015. 2018. Available from: https://ecdc. europa.eu/sites/portal/files/documents/AER_for_2015-HIV-AIDS.pdf.

7. Al-Tawfiq JA. Changes in the pattern of hospital intravenous antimicrobial use in Saudi Arabia, 2006-2008. Ann Saudi Med. 2012;32(5):517-20.
8. Soleymanzadeh-Moghadam S, Azimi L, Amani L, Rastegar LA, Alinejad F, Rastegar Lari A. Analysis of antibiotic consumption in burn patients. GMS Hyg Infect Control. 2015;10:Doc09.

9. AlShimemeri A, AlGhadeer $\mathrm{H}$, Memish Z. Antibiotic utilization pattern in a general medical ward of a tertiary medical center in Saudi Arabia. Avicenna J Med. 2011;1(1):8-11

10. Salehifar E, Nasehi M, Eslami G, Sahraei S, Navaei RA. Determination of antibiotics consumption in buali-sina pediatric hospital, sari 2010-2011. Iran J Pharm Res. 2014:13(3):995-1002

11. Hanberger $H$, Skoog G, Ternhag A, Giske CG. Antibiotic consumption and antibiotic stewardship in Swedish hospitals. Ups J Med Sci. 2014;119(2):154-61.

12. Al-Jumaili AA, Hussein AH, Al-Rekabi MD, Raheem SA, Ernst EJ. Antimicrobial utilization in an Iraqi province: A comprehensive evaluation of antibiotic source and cost. Int J Pharm Pract. 2017;25(1):81-8

13. Bozkurt F, Kaya S, Tekin R, Gulsun S, Deveci O, Dayan S, et al. Analysis of antimicrobial consumption and cost in a teaching hospital. J Infect Public Health. $2014 ; 7(2): 161-9$

14. Momattin H, Al-Ali AY, Mohammed K, Al-Tawfiq JA. Benchmarking of antibiotic usage: An adjustment to reflect antibiotic stewardship program outcome in a hospital in Saudi Arabia. J Infect Public Health. 2018;11(3):310-3.

15. Lee CF, Cowling BJ, Feng S, Aso H, Wu P, Fukuda K, et al. Impact of antibiotic stewardship programmes in Asia: A systematic review and meta-analysis. J Antimicrob Chemother. 2018;73(4):844-51.

16. Boyles TH, Whitelaw A, Bamford C, Moodley M, Bonorchis K, Morris V, et al. Antibiotic stewardship ward rounds and a dedicated prescription chart reduce antibiotic consumption and pharmacy costs without affecting inpatient mortality or re-admission rates. PLoS One. 2013;8(12):1-7.

17. Enani MA. The antimicrobial stewardship program in Gulf Cooperation Council (GCC) states: Insights from a regional survey. J Infect Prev. 2016;17(1):16-20. 